\title{
Psychogenic Tremor
}

National Cancer Institute

\section{Source}

National Cancer Institute. Psychogenic Tremor. NCI Thesaurus. Code C116725.

Paroxysmal movements, behaviors and sensations similar to a tremor but due to psychological distress instead of a neurological disorder. 